\title{
Increased risk of anxiety and depression associated with chronic pain and fibromyalgia in Pakistani population
}

\author{
Jibran S Muhammad ${ }^{1 *}$ and Muhammad Ishaq \\ ${ }^{1}$ Department of Basic Medical Sciences, College of Medicine, University of Sharjah, Sharjah, United Arab Emirates \\ ${ }^{2}$ Department of Internal Medicine, Jinnah Medical College Hospital, Karachi, Pakistan
}

\begin{abstract}
Objective: Fibromyalgia (FM) is reported to be strongly linked with anxiety and depression and is accompanied with the chronic antidepressant treatment. The aim of our study was to assess the frequency of fibromyalgia in patients presenting with chronic pain. Also, we assessed the prevalence of anxiety and depression in patients suffering from chronic pain compared to fibromyalgia.
\end{abstract}

Material and methods: A cross-sectional survey was conducted on 502 patients who presented at the rheumatology outpatient clinic of a tertiary-care hospital. Diagnosis of FM was based upon the defined criteria of American College of Rheumatology. Demographic data was collected using a pre-designed questionnaire. Whereas anxiety and depression were assessed using a preformed and previously validated Hospital-based Anxiety and Depression Scale (HADS).

Results: Results showed that a higher level of perceived pain (both chronic widespread pain or fibromyalgia pain) was significantly associated with a higher incidence of anxiety and depression in such patients. Furthermore, patients suffering from both chronic pain and high levels of anxiety and depression were at a higher increased risk of developing FM syndrome.

Conclusion: It was concluded that anxiety and depressive symptoms are significantly associated with increased pain perception, therefore anxiety and depression should be diagnosed and properly treated in order to improve FM symptoms for better quality of life.

\begin{abstract}
Abbreviations: FM: Fibromyalgia; HADS: Hospital Anxiety and Depression Scale; HADS-A: Anxiety; HADS-D: Hospital Anxiety and Depression Scale-depression; GAD: General Anxiety Disorder; SPSS: Statistical Package for the Social Sciences; BMI: Body Mass Index
\end{abstract}

\section{Introduction}

Fibromyalgia (FM), is a chronic musculoskeletal disorder, which is affecting approximately $3-10 \%$ of the general population. FM is characterized by symptoms of widespread chronic pain along with exaggerated tenderness in at least 11 out of 18 tender points [1]. At the time of diagnosis, depression and/or anxiety are present in $30-50 \%$ of FM patients [2]. FM patient frequently complains about disturbed sleep, morning stiffness, sensations of fatigue and irritable bowel syndrome, or symptoms of anxiety or depression [3]. It is a persistent and debilitating disorder that can have a devastating effect on patient's lives, affecting their ability to work and engage in everyday activities and relationships. Women are affected primarily with an incidence ranging between the ages of 40 to 49 years [4]. The prevalence of FM in a few European countries was reported with an estimate of 3\% $[5,6]$ and nearly $2 \%$ of the population is affected in the United States [7].

Characteristics of FM such as its complex and unknown etiology, its wide range of signs and symptoms, and multiple comorbidities, makes identification of effective therapies very difficult. Indeed, current treatment regimen has not proven to be effective in fully alleviating the symptoms of FM. Several pharmacological $[8,9]$ and non-pharmacological interventions have demonstrated some clinical benefits [10-12]. However, the treatment of FM is a challenge for clinicians and there is no consensus on the best therapeutic approach
[13]. FM is a known controversial illness like many other functional somatic syndromes. The patient generally looks well, and the laboratory investigations and radiologic findings are normal. Therefore, the diagnosis of an organic illness cannot be reached, and psychogenic or psychosomatic influences have been considered as the cause of FM. The pathophysiology of FM is focused on the presence of alterations in the central nervous system pain processing areas [14]. The mechanism of each symptom has not yet been fully established. In the presence of severe chronic pain and other somatic symptoms, disturbance of sleep and emotional alterations causes a great impact upon the patient's quality of life. In fact, FM affects the behavior of the patient, affecting daily life activities and negatively impacting occupational, personal and family life. At the end patient tries best to cope up with all the symptoms and disease limitations [15].

Frequencies of lifetime psychiatric disorders in FM patients compared to the subjects without a pain syndrome have been reported internationally. Patients from a tertiary care setting, who had not sought medical care for their symptoms, were significantly more often diagnosed having a depressive disorder, anxiety disorder, and

${ }^{*}$ Correspondence to: Jibran Sualeh Muhammad, Department of Basic Medical Sciences, College of Medicine, University of Sharjah, Sharjah, United Arab Emirates, Tel: 971-503746369; E-mail: dr.jibran@live.com

Key words: fibromyalgia, hospital-based anxiety and depression scale, quality of life, depression, anxiety

Received: February 05, 2019; Accepted: February 21, 2019; Published: February 25,2019 
somatization disorder compared with healthy controls [16]. However, no studies have so far investigated the frequency of FM and its effect on quality of life due to intolerable pain leading to anxiety and depression amongst the Pakistani population, especially the patients from the low socioeconomic background who are already living stressful lives.

The aim of this study was to assess the frequency of FM in patients presenting with chronic pain at a rheumatology outpatient clinic of a tertiary care hospital, located in a very low socioeconomic peripheral region of Karachi, Pakistan. In this study, we also aimed to evaluate the levels of anxiety and depression, in order to assess the quality of life in patients suffering from chronic pain and fibromyalgia in comparison to healthy controls.

\section{Materials and methods}

A hospital-based cross-sectional survey was conducted from January to December 2017 at a tertiary care teaching hospital. Jinnah Medical College hospital is located at a peripheral region of Karachi, providing health facilities to the adjoining slum areas with majority of the population living below the poverty line. The study site was selected purposely due to increasing number of patients being diagnosed with FM at consultant rheumatologic clinic in the Department of Medicine. All the patients, with a complaint of chronic joint pain, visiting outpatient service of rheumatology in the Department of Medicine were intended to be included. These patients went through a detailed medical history and clinical examination by a consultant rheumatologist.

In this descriptive study, 102 out of 502 patients (20.3\%) were diagnosed as FM. The diagnosis of FM was established based on the criteria defined by the American College of Rheumatology based on history and physical examination [17]. In remaining patients, 200 age-sex matched patients with chronic widespread pain but without FM were selected as chronic pain control. While 200 age-sex matched individuals were included from hospital staff and patient attendants as a healthy control. Both, male and female of 18 years of age or above, diagnosed cases of FM and in good general and cognitive status to understand and answer the questions were included in this study. Patients were given information on the study and those who agreed to participate were included in the study. Patients demographical data was obtained and recorded. History of the disease was documented from the patient's previous records, other related medical history was taken, and clinical examination was performed. Pain, fatigue, and frequencies sleep disturbance were explored using a short questionsanswer sheet. For sleep disturbance, the patient was asked questions regarding the number of nights in which there was difficulty falling asleep and the frequency of waking up in the middle of the night during the previous week only. Body diagrams were prepared for FM patients and the subjects were asked to indicate tender regions. Symptoms were queried in terms of FM. Patients were examined for tender points at 18 different points bilaterally and the number of tender points was recorded. Mental health status was assessed using previously validates Hospital Anxiety and Depression Scale (HADS) [18].

HADS is used widely in both epidemiological studies and psychology clinics. It is a brief self-rating scale to assess both categorical and dimensional aspects of anxiety and depression in both epidemiology and specialist care [18]. This scale (HADS) consists of seven questions for anxiety (HADS-A) and for depression (HADS-D), each. The answers give are scored using a four-point scale system; zero (not present) to three (considerable). These scores are then added, giving the total subscale scores on the HADS-A and the HADS-D ranging from zero to 21 . In this study, a valid score for each subscale was considered only if at least five of seven questions on both the subscales (HADS-A and the HADS-D) were answered. The HADS items were based on the psychological aspects of anxiety and depression to ensure its validity in patients with somatic problems. The questions related to anxiety were focused on assessing generalized anxiety disorder (GAD) and developed according to the diagnostic criteria of GAD. The questions related to depression were assessing anhedonia, which is an essential criterion for diagnosing depression [17]. The concurrent validity of the HADS compared to other questionnaires used to assess anxiety and depression was reported between 0.60 and 0.80 for each subscale, respectively [19].

Ethical approval was obtained from the Ethical Review Committee of Jinnah Medical College Hospital, Karachi, Pakistan. Written consent was attained where possible and verbal consent was given if the participants were illiterate. Privacy was attempted while administering the questionnaires and participants were interviewed by an interviewer of the same gender. Personal information is an important part of the study and as such assurance was given to participants that their name, age, occupation, and gender, will not be disclosed. Microsoft Excel was used for data entry and Statistical Package for the Social Sciences (SPSS) version 19.0 was used for data analysis. Descriptive statistics were used to characterize the sample. Chi-square test was used for categorical variables. The $p$-value $<0.05$ was considered significant. Frequencies and proportions of qualitative and quantitative variables are presented. Mean and standard deviation are used to assess quantitative measures.

\section{Results}

\section{Demographic data}

Out of 102 fibromyalgia patients who were included in our study, $88.2 \%$ were women with the mean age of $50 \pm 9.27$ years and $45.1 \%$ were employed. Mean duration of the onset of pain was $11.01 \pm 1.97$ years with the range of 1-20 years. Remaining patients who presented with chronic pain were recruited in equal gender proportion as a positive control for the FM group. Healthy controls were recruited from the hospital staff or patient attendants as negative control subjects for the FM group. The weight of the patient might have some role in symptoms aggravation in fibromyalgia. There we calculated the body mass index (BMI) of all the participants included in our study. We found that the BMI of fibromyalgia patients was slightly higher than controls $(30.1 \mathrm{~kg} /$ $\mathrm{m}^{2}$ vs. $25.8 \mathrm{~kg} / \mathrm{m}^{2}$ respectively with $p \leq 0.001$ ). Differences in educational status between the subjects were also observed. Majority of FM patients who received education up till graduation was compared to the control group $(p<0.01)$. Majority of the subjects had received education only up till higher secondary level and all the study subjects belonged from a population of low socioeconomic status. Demographic characteristics of participants are summarized in table 1 .

\section{Level of anxiety in FM}

In order to assess anxiety and depression, we utilized a pre-defined HADS scale. Patients suffering from FM showed severe anxiety compared to healthy subjects. As highlighted in table 2, higher numbers of FM patients were suffering from hospital-based anxiety compared to the control group ( $16.6 \%$ versus $2 \%$ respectively). Similarly, a number of FM patients suffering from anxiety were a lot higher than patients with chronic widespread pain ( $16.6 \%$ vs $11 \%$, respectively, table 3$)$. FM patients who showed normal levels of anxiety were mostly married and employed. However, several married couples were also experiencing hospital-based anxiety due to chronic widespread pain compared to healthy controls (Table 4). 
Table 1. Demographic characteristics of fibromyalgia patients, chronic pain patients and healthy control $(\mathrm{n}=502)$.

\begin{tabular}{|l|c|c|c|}
\hline & $\begin{array}{c}\text { FM \% } \\
(\mathbf{n}=\mathbf{1 0 2})\end{array}$ & $\begin{array}{c}\text { Chronic pain \% } \\
(\mathbf{n}=\mathbf{2 0 0})\end{array}$ & $\begin{array}{c}\text { Healthy control \% } \\
(\mathbf{n}=\mathbf{2 0 0})\end{array}$ \\
\hline Gender & & & 50.0 \\
\hline Male & 11.8 & 50.0 & 50.0 \\
\hline Female & 88.2 & 50.0 & 15.0 \\
\hline Age group & & & 25.0 \\
\hline $18-25$ years & 20.6 & 12.5 & 19.0 \\
\hline 26-35 years & 35.3 & 16.0 & 21.0 \\
\hline $36-45$ years & 16.6 & 32.0 & 20.0 \\
\hline $46-55$ years & 11.8 & 33.5 & 8.0 \\
\hline$>55$ years & 15.7 & & 60.0 \\
\hline Education & & 21.5 & 32.0 \\
\hline Primary & 14.7 & 58.0 & 29.0 \\
\hline Secondary & 38.2 & 20.5 & 51.0 \\
\hline Graduate & 47.1 & & 10.0 \\
\hline Marital status & & 14.0 & 10.0 \\
\hline Single & 40.2 & 69.0 & 65.5 \\
\hline Married & 40.2 & 3.0 & 34.5 \\
\hline Divorced & 13.8 & 14.0 & \\
\hline Widowed & 5.8 & 25.5 & \\
\hline Employment & & 74.5 & \\
\hline Employed & 45.1 & & \\
\hline Unemployed/House & 54.9 & & \\
\hline wife & & & \\
\hline
\end{tabular}

Table 2. HAD scale score comparison of FM and healthy control for generalized anxiety disorder

\begin{tabular}{|c|c|c|c|}
\hline $\begin{array}{c}\text { Score } \\
\text { (HADS-Anxiety) }\end{array}$ & $\begin{array}{c}\text { FM \% } \\
(\mathbf{n = 1 0 2})\end{array}$ & $\begin{array}{c}\text { Healthy control \% } \\
(\mathbf{n = 2 0 0})\end{array}$ & $\boldsymbol{P}$-value \\
\hline Normal (0-7 score) & $26.47 \%(27)$ & $73.0 \%(146)$ & $<0.001$ \\
\hline Mild (8-10 score) & $12.74 \%(13)$ & $20.0 \%(40)$ & 0.117 \\
\hline Moderate(11-15 score) & $44.11 \%(45)$ & $5.0 \%(10)$ & $<0.001$ \\
\hline Severe (16-21 score) & $16.66 \%(17)$ & $2.0 \%(4)$ & $<0.001$ \\
\hline
\end{tabular}

Table 3. HAD scale score comparison of FM and chronic pain patients for generalized anxiety disorder.

\begin{tabular}{|c|c|c|c|}
\hline $\begin{array}{c}\text { Score } \\
\text { (HADS-Anxiety) }\end{array}$ & $\begin{array}{c}\text { FM \% } \\
(\mathbf{n = 1 0 2})\end{array}$ & $\begin{array}{c}\text { Chronic pain \% } \\
(\mathbf{n = 2 0 0 )}\end{array}$ & $\boldsymbol{P}$-value \\
\hline Normal (0-7 score) & $26.47 \%(27)$ & $40.0 \%(80)$ & 0.131 \\
\hline Mild (8-10 score) & $12.74 \%(13)$ & $34.0 \%(68)$ & 0.002 \\
\hline Moderate (11-15 score) & $44.11 \%(45)$ & $15.0 \%(30)$ & $<0.001$ \\
\hline Severe (16-21 score) & $16.66 \%(17)$ & $11.0 \%(22)$ & 0.168 \\
\hline
\end{tabular}

Table 4. HAD scale score comparison of healthy control and chronic pain patients for generalized anxiety disorder

\begin{tabular}{|c|c|c|c|}
\hline $\begin{array}{c}\text { Score } \\
\text { (HADS-Anxiety) }\end{array}$ & $\begin{array}{c}\text { Healthy control \% } \\
(\mathbf{n = 2 0 0}\end{array}$ & $\begin{array}{c}\text { Chronic pain \% } \\
(\mathbf{n = 2 0 0 )}\end{array}$ & $\boldsymbol{P}$-value \\
\hline Normal (0-7 score) & $73.0 \%(146)$ & $40.0 \%(80)$ & $<0.001$ \\
\hline Mild (8-10 score) & $20.0 \%(40)$ & $34.0 \%(68)$ & 0.036 \\
\hline Moderate (11-15 score) & $5.0 \%(10)$ & $15.0 \%(30)$ & 0.001 \\
\hline Severe (16-21 score) & $2.0 \%(4)$ & $11.0 \%(22)$ & $<0.001$ \\
\hline
\end{tabular}

\section{Level of depression in FM}

When dealing with chronic pain illnesses, it is very common for patients to develop depression. Depression is prominent in FM, and it is of higher risk that FM patient can develop major depressive episodes during their lifetime. Patients suffering from FM showed severe depression (20\%) compared to healthy control group (3\%) as shown in table 5. Similarly, number of FM patients suffering from depression were significantly higher than patients with chronic widespread pain ( $20.5 \%$ vs $13 \%$, respectively, table 6 ). Higher level of depression was not associated with marital status. However, patients with higher levels of anxiety were also suffering from severe depression (Table 7).

\section{Discussion}

Chronic widespread pain, such as seen in fibromyalgia, is known to be associated with several comorbidities which could directly affect the overall quality of the patient's life and the also the life of their dependents. Two of the most common comorbidities are anxiety and depression [20,21]. FM is reported to be strongly linked with anxiety and depression and is accompanied with the chronic antidepressant treatment [22]. Many FM patients also suffer from comorbidities such as psychiatric disorders and present a diagnostic dilemma requiring consideration for additional unnecessary treatment options to optimize patient outcomes [23]. Furthermore, the FM patients' present with more psychological symptoms such as anxiety and depression compared to the patients having the pain of neurotic origin. Therefore, the effect of intensity of chronic pain is directly associated with the mood changes in fibromyalgia patients [24]. Moreover, it was proven that the negative mood changes in those patients make them unable to properly perceive their own physical health. However, it did not show any positive effect on their pain assessment by a physician [25]. This might be a possible reason for their late presentation in the clinics despite the seriousness of their condition.

Our study showed that fibromyalgia patients, especially women, perceived higher intensity pain if they were also suffering from high levels of anxiety or depression. Furthermore, high scores in the HADS scale (both anxiety and depression scales) was strongly associated with increased risk of perceiving intense pain in fibromyalgia patients. Fibromyalgia patients suffer more from psychological distress, such as anxiety or depression, compared to a person without fibromyalgia [24]. In this study, we observed that the mean values of anxiety or depression scores on HADS scale were not pathological (scores >16), in contrast, few studies showed that fibromyalgia patients in their study were suffering from severe anxiety or depression [24]. Similarly, one other

Table 5. HAD scale score comparison of FM and healthy control for major depressive episodes

\begin{tabular}{|c|c|c|c|}
\hline $\begin{array}{c}\text { Score } \\
\text { (HADS-Depression) }\end{array}$ & $\begin{array}{c}\text { FM \% } \\
(\mathbf{n = 1 0 2})\end{array}$ & $\begin{array}{c}\text { Healthy control \% } \\
(\mathbf{n = 2 0 0}\end{array}$ & $\boldsymbol{P}$-value \\
\hline Normal (0-7 score) & $23.5 \%(24)$ & $77.0 \%(154)$ & $<0.001$ \\
\hline Mild (8-10 score) & $19.6 \%(20)$ & $13.0 \%(26)$ & 0.206 \\
\hline Moderate (11-15 score) & $36.4 \%(37)$ & $7.0 \%(14)$ & $<0.001$ \\
\hline Severe (16-21 score) & $20.5 \%(21)$ & $3.0 \%(6)$ & $<0.001$ \\
\hline
\end{tabular}

Table 6. HAD scale score comparison of FM and chronic pain patients for major depressive episodes

\begin{tabular}{|c|c|c|c|}
\hline $\begin{array}{c}\text { Score } \\
\text { (HADS-Depression) }\end{array}$ & $\begin{array}{c}\text { FM \% } \\
(\mathbf{n = 1 0 2})\end{array}$ & $\begin{array}{c}\text { Chronic pain \% } \\
(\mathbf{n = 2 0 0})\end{array}$ & P-value \\
\hline Normal (0-7 score) & $23.5 \%(24)$ & $39.0 \%(78)$ & 0.007 \\
\hline Mild (8-10 score) & $19.6 \%(20)$ & $31.0 \%(62)$ & 0.035 \\
\hline Moderate (11-15 score) & $36.4 \%(37)$ & $17.0 \%(34)$ & $<0.001$ \\
\hline Severe (16-21 score) & $20.5 \%(21)$ & $13.0 \%(26)$ & 0.008 \\
\hline
\end{tabular}

Table 7. HAD scale score comparison of healthy control and chronic pain patients for major depressive episodes

\begin{tabular}{|c|c|c|c|}
\hline $\begin{array}{c}\text { Score } \\
\text { (HADS-Depression) }\end{array}$ & $\begin{array}{c}\text { Healthy control \% } \\
(\mathbf{n = 2 0 0 )}\end{array}$ & $\begin{array}{c}\text { Chronic pain \% } \\
(\mathbf{n = 2 0 0}\end{array}$ & P-value \\
\hline Normal (0-7 score) & $77.0 \%(154)$ & $39.0 \%(78)$ & $<0.001$ \\
\hline Mild (8-10 score) & $13.0 \%(26)$ & $31.0 \%(62)$ & $<0.001$ \\
\hline Moderate (11-15 score) & $7.0 \%(14)$ & $17.0 \%(34)$ & 0.002 \\
\hline Severe (16-21 score) & $3.0 \%(6)$ & $13.0 \%(26)$ & $<0.001$ \\
\hline
\end{tabular}


study reported that more than $80 \%$ of the fibromyalgia patients showed severe symptoms of clinical depression [26].

Daily life is more stressful in fibromyalgia patients compared to a normal individual [27]. This phenomenon is might be because of their tendency to overrate and exaggerate otherwise mild stressful events as a more severe for them. Due to an increased perception of stress, a higher number of depressive events were seen in fibromyalgia patients. Several other studies have explored the relationship between pain and depression in fibromyalgia patients especially focusing on the influence of depression on the processing of such chronic pain condition. In a study by Aguglia et al. [3] fibromyalgia patients they recruited with depression displayed a much poor quality of life compared to those who did not show any depressive symptoms. On the other hand, Jensen et al. [24] concluded that depression or anxiety was not directly associated with chronic widespread pain or fibromyalgia. Also, they rejected the use of an effective pain modulation therapy in fibromyalgia patients. Instead, the significant correlation between depression, anxiety and the subjective rating on one's health that they obtained suggested negative mood which affects the perception of the health status of the patient. The negative mood in FM patients could thus lead to a poor perception of the physical health but not to poor performance in clinical and experimental pain assessments as tenderness. A similar study performed in rheumatoid arthritis patients showed no relationship between depressive symptoms and cerebral pain processing in rheumatoid arthritis patients during experimental pain [26,27].

There have been speculations about a generally exaggerated emotional response among FM patients, suggesting that FM was a virtual disease, caused by psychological vulnerability [28]. However, the effects of antidepressants on pain seem to be independent of mood, since the antidepressant and analgesic effects are independent of each other in clinical trials [29]. On the other hand, the role of psychological factors in the pathogenesis of FM is also controversial. Depressive symptoms are often present, but it has been difficult to determine if depressive disorders are a primary cause of FM or a reaction to the debilitating symptoms of this disease [30]. Another explanation for the higher perception of pain in FM patients with depressive symptoms is the tendency of depressed patients to adopt coping strategies [24]. Depression and coping strategies adoption are critically important variables in understanding the experience of pain in patients with rheumatologic disorders. Pain, depression, and catastrophizing might all be uniquely important therapeutic targets in the multimodal management of FM [31].

The inclusion of more female FM patients could be a limitation of this study and thus, specific research on depression and anxiety presence and its relationship with pain in male FM patients are needed. On the other hand, the strength of this study was that we have compared the depression and anxiety levels in FM patients with patients suffering from chronic widespread pain in order to validate the debilitating effects of FM. Overall, the higher perceived pain was associated with high levels of anxiety and depression but not with higher tenderness. Furthermore, patients suffering from both chronic pain and high levels of anxiety and depression presented an increased risk of developing FM syndrome.

\section{Conclusion}

It was concluded that anxiety and depressive symptoms are significantly associated with increased pain perception, therefore anxiety and depression should be diagnosed and properly treated in order to improve FM symptoms for better quality of life. Considering the results of this study, it would be of interest to analyze if psychological interventions focusing on alleviation of anxiety and depression could also reduce the severity and pain in FM patients.

\section{Ethical approval and consent to participate}

All procedures performed in this study involving human subjects were in accordance with the institutional research committee ethical standards and ethical approval was obtained from the ethical review committee of Jinnah Medical College Hospital, Karachi, Pakistan. Informed consent was obtained from all individual participants included in the study.

\section{Disclosure}

Abstract of this study was presented at the $19^{\text {th }}$ Asia Pacific League of Associations for Rheumatology Congress (APLAR), 16-20 October 2017, Dubai, UAE, October 2017.

\section{Acknowledgments}

We are thankful to Mohamad Shahzeb Ali and Farhan Khalid for their efforts in data collection and entry. We also acknowledge the contribution of all the study participants at Jinnah Medical College Hospital, Karachi, Pakistan.

\section{References}

1. Walitt B, Nahin RL, Katz RS, Bergman MJ, Wolfe F (2015) The Prevalence and Characteristics of Fibromyalgia in the 2012 National Health Interview Survey. PLoS One 10: e0138024. [Crossref]

2. Weir PT, Harlan GA, Nkoy FL, Jones SS, Hegmann KT, et al. (2006) The incidence of fibromyalgia and its associated comorbidities: a population-based retrospective cohort study based on International Classification of Diseases, 9th Revision codes. J Clin Rheumatol 12: 124-128. [Crossref]

3. Aguglia A, Salvi V, Maina G, Rossetto I, Aguglia E (2011) Fibromyalgia syndrome and depressive symptoms: comorbidity and clinical correlates. $J$ Affect Disord 128 : 262-266. [Crossref]

4. Ting TV, Barnett K, Lynch-Jordan A, Whitacre C, Henrickson M, et al. (2016) 2010 American College of Rheumatology adult fibromyalgia criteria for use in an adolescent female population with juvenile fibromyalgia. J Pediatr 169: 181-187.e1. [Crossref]

5. Branco JC, Bannwarth B, Failde I, Abello Carbonell J, Blotman F, et al. (2010) Prevalence of fibromyalgia: a survey in five European countries. Semin Arthritis Rheum 39: 448-453. [Crossref]

6. Bannwarth B, Blotman F, Roué-Le Lay K, Caubère JP, André E, et al. (2009) Fibromyalgia syndrome in the general population of France: a prevalence study. Joint Bone Spine 76: 184-187. [Crossref]

7. Chakrabarty S, Zoorob R (2007) Fibromyalgia. Am Fam Physician: 76.

8. Goldenberg DL, Burckhardt C, Crofford L (2004) Management of fibromyalgia syndrome. JAMA 292: 2388-2395. [Crossref]

9. Häuser W1, Bernardy K, Uçeyler N, Sommer C (2009) Treatment of fibromyalgia syndrome with antidepressants: a meta-analysis. JAMA 301: 198-209. [Crossref]

10. Burckhardt CS (2006) Multidisciplinary approaches for the management of fibromyalgia. Curr Pharm Des 12: 59-66. [Crossref]

11. Häuser W, Bernardy K, Arnold B, Offenbächer M, Schiltenwolf M (2009) Efficacy of multicomponent treatment in fibromyalgia syndrome: a meta-analysis of randomized controlled clinical trials. Arthritis Rheum 61: 216-224. [Crossref]

12. van Koulil S, Effting M, Kraaimaat FW, van Lankveld W, van Helmond T, et al. (2007) Cognitive behavioral therapies and exercise programmes for patients with fibromyalgia: state of the art and future directions. Ann Rheum Dis 66: 571-581. [Crossref]

13. Berger A, Dukes E, Martin S, Edelsberg J, Oster G (2007) Characteristics and healthcare costs of patients with fibromyalgia syndrome. Int J Clin Pract 61: 14981508. [Crossref]

14. Phillips K, Clauw DJ (2011) Central pain mechanisms in chronic pain states maybe it is all in their head. Best Pract Res Clin Rheumatol 25: 141-154. [Crossref] 
15. Taylor AG, Fischer-White TG, Anderson JG, Adelstein KE, Murugesan M, et al. (2016) Stress, Inflammation, and Pain: A Potential Role for Monocytes in Fibromyalgia related Symptom Severity. Stress Health 32: 503-513. [Crossref]

16. Edwards TM, Stern A, Clarke DD, Ivbijaro G, Kasney LM (2010) The treatment of patients with medically unexplained symptoms in primary care: a review of the literature. Ment Health Fam Med 7: 209. [Crossref]

17. Wolfe F, Clauw DJ, Fitzcharles MA, Goldenberg DL, Katz RS, et al. (2010) The American College of Rheumatology preliminary diagnostic criteria for fibromyalgia and measurement of symptom severity. Arthritis Care Res (Hoboken) 62: 600-610. [Crossref]

18. Mykletun A, Stordal E, Dahl AA (2001) Hospital Anxiety and Depression (HAD) scale: factor structure, item analyses and internal consistency in a large population. $\mathrm{Br}$ J Psychiatry 179: 540-544. [Crossref]

19. Zigmond AS, Snaith RP (1983) The hospital anxiety and depression scale. Acta Psychiatr Scand 67: 361-370. [Crossref]

20. Moorey S, Greer S, Watson M, Gorman C, Rowden L, et al. (1991) The factor structure and factor stability of the hospital anxiety and depression scale in patients with cancer. Br J Psychiatry 158: 255-259. [Crossref]

21. Watson D, Clark LA, Weber K, Assenheimer JS, Strauss ME, et al. (1995) Testing a tripartite model: II. Exploring the symptom structure of anxiety and depression in student, adult, and patient samples. J Abnorm Psychol 104: 15. [Crossref]

22. Bjelland I, Dahl AA, Haug TT, Neckelmann D (2002) The validity of the Hospital Anxiety and Depression Scale: an updated literature review. J Psychosom Res 52: 6977. [Crossref]
23. Perret D, Rosen C (2011) A physician-driven solution--the Association for Medical Ethics, the Physician Payment Sunshine Act, and ethical challenges in pain medicine. Pain Med 12: 1361-1375. [Crossref]

24. Jensen KB, Petzke F, Carville S, Fransson P, Marcus H, et al. (2010) Anxiety and depressive symptoms in fibromyalgia are related to poor perception of health but not to pain sensitivity or cerebral processing of pain. Arthritis Rheum 62: 3488-3495. [Crossref]

25. Schulz R, Sherwood PR (2008) Physical and mental health effects of family caregiving. Am J Nurs 108: 23-27. [Crossref]

26. Taylor AG, Adelstein KE1, Fischer-White TG1, Murugesan M1, Anderson JG1 (2016) Perspectives on Living with Fibromyalgia. Glob Qual Nurs Res 3: 2333393616658141. [Crossref]

27. Giesecke T, Gracely RH, Williams DA, Geisser ME, Petzke FW, et al. (2005) The relationship between depression, clinical pain, and experimental pain in a chronic pain cohort. Arthritis Rheum 52: 1577-1584. [Crossref]

28. Arnold LM (2008) Management of fibromyalgia and comorbid psychiatric disorders. $J$ Clin Psychiatry 69 Suppl 2: 14-19. [Crossref]

29. Jensen KB, Petzke F, Carville S, Choy E, Fransson P, et al. (2014) Segregating the cerebral mechanisms of antidepressants and placebo in fibromyalgia. J Pain 15: 1328 1337. [Crossref]

30. Hidaka BH (2012) Depression as a disease of modernity: explanations for increasing prevalence. J Affect Disord 140: 205-214. [Crossref]

31. Edwards RR, Cahalan C, Mensing G, Smith M, Haythornthwaite JA (2011) Pain catastrophizing, and depression in the rheumatic diseases. Nat Rev Rheumatol 7: 216224. [Crossref]

Copyright: (C2019 Muhammad JS. This is an open-access article distributed under the terms of the Creative Commons Attribution License, which permits unrestricted use, distribution, and reproduction in any medium, provided the original author and source are credited. 